\title{
Unpacking 'ethno-finance': an introduction to indigenous 'financial' knowledge systems
}

\author{
R.J.C. Bray \\ Department of Finance and Investment Management \\ University of Johannesburg \\ South Africa \\ bray.richard@gmail.com \\ G. Els \\ Department of Finance and Investment Management \\ University of Johannesburg \\ South Africa \\ gels@uj.ac.za
}

For too many individuals, indigenous knowledge systems provoke no enthusiasm as they are perceived to be dormant and irrelevant. This article attempts to change this perception by highlighting the need for an in-depth knowledge of indigenous knowledge systems and, moreover, indigenous knowledge systems within finance. A comprehensive definition of ethno-finance, as well as examples, is supplied to help in the development of research opportunities within the sub-field of ethno-finance regarding indigenous knowledge systems.

Key words: Indigenous knowledge systems, indigenous knowledge, ethno-finance, IK, IKS

Received 19 September 2006; accepted January 2007

\section{Contents}

1. Introduction

2. Indigenous knowledge systems

2.1 Defining some concepts

2.2 Relevance of indigenous knowledge

3. Historical perceptions on indigenous knowledge

3.1 Introduction

3.2 Evolution of perceptions

4. Studying indigenous knowledge systems in finance

4.1 Ethno-finance defined

4.2 Can 'ethno-finance' as a sub-field add value? 
4.3 Evidence of ethno-finance in South Africa

5. Researching ethno-finance as an evolving topic

6. Conclusion

7. Acknowledgement

8. References

\section{Introduction}

Indigenous knowledge systems have been evident in the fields of medicine and agriculture for many years (Adjibade 2003; Norman, Snyman and Cohen 1996). The research collected and developed has offered invaluable advice and advancements in those particular sectors. The question arises as to what other sectors could possibly gain in terms of the inquest into indigenous knowledge systems.

Throughout Africa, poverty has hindered developing economies from keeping up with global development. For this reason, if finance in terms of lending and saving can be understood and viewed other than in a 'westernized' way, it could perhaps help alleviate and bring about a better understanding towards the alleviation of poverty.

The aim of this article is to attempt to qualify the 'science' of indigenous knowledge by focusing on the unresearched field of finance within indigenous knowledge systems, that is indigenous financial knowledge systems, and to show that a 'new' field of study, namely 'ethno-finance', may be applicable within the studies of indigenous knowledge systems. This may also help identify research opportunities that exist within the southern African region pertaining to financial practices as implemented by various indigenous groups.

$\longrightarrow$ top

\section{Indigenous knowledge systems}

\subsection{Defining some concepts}

Knowledge may be defined as 'the state or fact of knowing something with familiarity, awareness, or understanding gained through experience or association' (Merriam-Webster 2006). Knowledge, as defined above, may be interpreted as an indigenous 'science', seeking to understand, explain and organize aspects of reality.

Tacit knowledge is the knowledge that people acquire that cannot be readily or effortlessly written down. When knowledge is therefore implied by or inferred from actions or statements, it is said to be tacit. This is due to tacit knowledge being based on people's skills (Gardner 1987). It is a silent knowledge that emerges only when a person is doing something that requires such knowledge or when they are reminded of it. Whatever governs this knowledge, it is not conscious, nor is it a knowledge that can be disclosed through a system or an outline in a book.

Knowledge systems are systems through which people make sense of and attach meaning to the world in which they live. These views and perceptions originate within a specific community or culture and are handed down from generation to generation (Kok 2005), resulting in personal experiences and wisdom being transferred to younger people. These knowledge systems reflect the dynamic way in which the residents of a community come to understand themselves in relation to their natural environment and how they organize that knowledge of flora, fauna, cultural beliefs and history to enhance their lives. These personal 
experiences, wisdom and order of knowledge represent the mechanisms that ensure the minimal livelihoods of people (Dei 1999).

In the Western context, the term 'indigenous' has often been associated with the primitive, the wild and the natural (Dei 1999). This is misleading, as indigenous may be defined as originating and living or occurring naturally in an area or environment (Wikipedia 2006), that is, being native to the environment even if that environment is within a high density modern city. It embodies the philosophy that being one's own is a result of the place or circumstances of one's birth, which encompasses being a member of the original inhabitants or lifelong resident of a particular place. This may imply that all racial cultures represented by one or more of the eleven official languages can be considered indigenous to South Africa, for example.

The problem with indigenous knowledge systems is that no formal, all-encompassing definition exists (World Bank 1998). This may be due to the broad fields that indigenous knowledge systems cover, ranging from anthropology to agricultural engineering. Warren (1991) believes that indigenous knowledge is 'local knowledge' that is unique to a given culture or society. Flavier (1995) expanded this interpretation by stating that indigenous knowledge 'is the information base for a society which facilitates communication and decision-making'. According to Havekort (1991), indigenous knowledge is the actual knowledge of a given population that reflects the experiences based on traditions and includes more recent experiences with modern technologies. Butler and Waud (1990) reiterated this by stating that those involved within these experiences are well informed about their own situations, their resources, and 'how to change an impact on other parts of their systems' (Rajasekaran 1993).

Broadly speaking, indigenous knowledge systems refer to the complex set of knowledge and technologies existing and developed around specific conditions of populations and communities indigenous to a particular area. These indigenous knowledge systems provide 'an everyday realisation that rewards individuals who live in a given locality'. From a South African perspective, research by Loubser (2004) on indigenous knowledge systems describes 'indigenous' as being 'communities that inhabit the country at the time of conquest or colonization'. In South Africa therefore an indigenous knowledge system is a body of knowledge embedded in African philosophical thinking and social practices that have evolved over thousands of years (Loubser 2004). These African philosophies are inclusive of all cultural groups in South Africa.

\subsection{Relevance of indigenous knowledge}

Indigenous knowledge may be seen as relevant on three different levels within the sustainable development process (World Bank 1998) and these are the:

- local community - where the bearers of such knowledge live and produce;

- various development agents (e.g. governments, donors, local leaders and private sector initiatives). These agents need to recognize it, value it and appreciate it in their interaction with the local communities. Before incorporating it in their approaches, they need to understand it and critically validate it against the usefulness for their intended objectives; and

- global knowledge. Indigenous knowledge forms part of it and in this context it has a value and relevance in itself. Indigenous knowledge can be conserved, transferred, or adopted and adapted elsewhere.

The above has shown the relevance of indigenous knowledge but if one considers its historical development the same may not be true. 


\section{Historical perceptions on indigenous knowledge}

\subsection{Introduction}

The general historical attitude towards indigenous knowledge used to be that it was primitive, unproductive and irrelevant. It was viewed as part of a mysterious past and a major obstacle in the development of third-world countries, instead of a critical evolving component of a cultural alternative to modernization.

Previously, intelligence in the western world was measured and valued according to logical, mathematical and specific abilities. Intelligence was a measure of how well an individual or group adapted to and handled western culture (Gardner 1987). This resulted in a knowledge paradigm that focused on using laboratories, researchers and higher education intuitions for developing knowledge instead of developing knowledge through personal and historical practices.

Over the years, however, multiple indigenous practices and knowledge systems have been studied extensively. These studies have been conducted by sectoral specialists (e.g. in agriculture) and have provided invaluable information. The complication is that all these studies concentrated primarily on social or ethnological aspects of knowledge instead of the more technical issues.

\subsection{Evolution of perceptions}

The theory of multi-intelligence emerged in the 1960s and forced educationalists to recognize that there is more than one way to process information (Els and Van Schalkwyk 2006). This theory highlights the many ways in which different cultures show their capacities (Gardner 1987).

Approximately ten years ago, Howard Gardner, a professor of education at Harvard University, developed a model to assist in the development of theories surrounding multiintelligences (Dei 1999). This revolutionary model was built by categorizing the broad range of human abilities into seven basic intelligences. These are described as follows:

- Linguistic: the intelligence of words

- Logical-mathematical: the intelligence of numbers and reasoning

- Spatial: the intelligence of pictures and images

- Musical: the intelligence of tone, rhythm, and timbre

- Bodily kinaesthetic: the intelligence of the whole body and the hands

- Interpersonal: the intelligence of social understanding

- Intrapersonal: the intelligence of self-knowledge.

Owing to the recognition for the need to understand multi-intelligences, educationalists now have a map for making sense out of the many ways in which children learn and a blueprint for ensuring their success in school and in life. This illustration of the development of basic intelligence also emphasizes the importance and urgency with which 'ethno-finance' must be developed as it may be regarded as one of the multi-faceted aspects of indigenous knowledge.

Greater recognition of the wide diversity and use of knowledge systems has resulted in indigenous knowledge being regarded as an integral part of the development process of local communities. The 1998/1999 World Development Report (World Bank 1998) commissioned 
by the World Bank indicates that knowledge, not capital, is the key to sustainable social and economic development. It goes on to emphasize the importance of indigenous knowledge systems in building local knowledge, which is the first step in mobilizing such 'knowledge' capital. This report also focuses on how to integrate indigenous knowledge to improve the benefits of development assistance in developing countries.

\section{Studying indigenous knowledge systems in finance}

\subsection{Ethno-finance defined}

It has been conferred above that many factors and spheres are included under the broad definition of indigenous knowledge systems. If the focus shifts to finance (e.g. saving and lending), it may be incorporated into one term referred to as indigenous financial knowledge systems. An indigenous financial knowledge system can be classified as a sub-system of indigenous knowledge systems because it will be defined in terms of the broader description of indigenous knowledge systems by focusing on its salient features.

Finance may be defined as the science or art of managing money, assets and other monetary resources of an organization, country or person (Wikipedia 2006). The World Bank (1998) furthermore pointed out that in an emerging global knowledge economy, a country's ability to build and mobilize knowledge capital is equally essential for sustainable development as the availability of physical and financial capital. By focusing on indigenous financial knowledge, we are able to understand the indigenous knowledge derived to deal with the alleviation of poverty and thereby incorporate an aspect of sustainable development.

Various systems are presented in southern Africa where people indigenous to the region treat their finances in a way according to traditional practices and customs. Any object or practice from a particular area that denotes or derives itself from the cultural traditions of a group of people is viewed as ethnic (Wikipedia 2006). It does not only apply to African culture but to all cultural traditions that have developed over multiple racial and culture groups. This ties in with the term 'indigenous' in that it may refer to an object originating and living in an area.

These 'objects' can be classified as ethnic as they are derived from the cultural traditions of a group of people. If the 'object' is identified as finance, then it is safe to say that ethno-finance is the art of managing money and assets within a financial system that originates and develops from a specific area and denotes or derives itself from the cultural traditions of the people who live in that specific geographical area.

\subsection{Can ethno-finance as a sub-field add value?}

The work of Abrahams (1987), Oladimeji (1987), McNeely (1989), Munyakho (1994) and Sindiga (1995) emphasizes the fact that indigenous knowledge systems exist in all spheres of life including education, socio-economic, health, engineering, politics, agriculture and even sports.

Indigenous knowledge is of particular relevance to poorer communities in terms of:

- Agriculture

- Use and management of natural resources

- Veterinary medicine

- Primary health care

- Community development 
- Saving

- Lending.

With such diverse fields, is ethno-finance feasible? Indigenous knowledge is often viewed as an ambiguous topic that immediately places analysts on dangerous terrain. Wane (2005) believes that the debate is intellectually stimulating and warrants reflection despite its complexity. A greater understanding of indigenous epistemology will also provide scholars with an alternative perception of knowledge production originating from other cultural groups.

Epistemology is a branch of philosophy that addresses the philosophical problems surrounding the theory of knowledge. Epistemology is concerned with the explanation of knowledge and related concepts, the sources and criteria of knowledge, the kinds of knowledge possible and the degree to which each is certain, as well as the exact relation between the one who knows and the object known (Merriam-Webster 2006).

An understanding of ethno-finance may be instrumental in the evolution of a more comprehensive educational system and provide the government with a new intermittent approach towards the development of economic policies. Both these factors will add value through a broader awareness of finance, which will inevitably lead to greater social and economic development. This was already highlighted in section 3.2 of this article.

\subsection{Evidence of ethno-finance in South Africa}

A large proportion of the black population of South Africa are involved in informal economic activities, including retailing, agriculture and small-scale manufacturing. Morris and Pitt (1995) report that about 22\% of the active black population is deemed to be involved in informal activities such as trading and hawking (55\%), production and construction (23\%), services (16\%) and illicit activities (6\%). The informal sector provides a wide range of goods and services to mostly the black community. A handful of these goods and services are briefly listed below:

- The use of 'stokvels' (a savings association) as an informal vehicle that can aid in overcoming low levels of income that requires committed saving

- Village banks and burial societies (Irving 2005)

- The payment of 'lobola' (a cultural marriage tax)

- The management of a 'shebeen' (an 'illegal' bar)

- Profit made from a spaza by selling sweets, cigarettes and food on a street corner, for example by an informal trader.

\section{Researching ethno-finance as an evolving topic}

Although indigenous knowledge systems were perceived as dominant or static (Ellen and Harris 1996), evolution is a key feature of knowledge systems. This is evident in that indigenous knowledge is constantly changing by being produced and reproduced; and/or discovered and lost. The transformations and evolution of indigenous knowledge systems has taken place through indigenous mechanisms of creativity and innovation as well as contact and influence from other local and internal knowledge systems, resulting in indigenous knowledge systems being viewed as dynamic and relevant (Els and Van Schalkwyk 2006).

From a South African perspective, an indigenous knowledge system is a body of knowledge that is embedded in African philosophical thinking and social practices that have evolved 
over thousands of years. When concentrating on the financial aspect of indigenous knowledge systems, it can be defined as ethno-finance, which is the art of managing money and assets within a financial system that originates and develops from a specific area and denotes or derives itself from the cultural traditions of the people who live in that specific geographical area.

The typical top-down approach towards learning is not evident within ethno-finance. Ethnofinance comes about from within a community by being experimental and repetitious; it evolves over time into a financial system that is acceptable and profitable for all involved. Focusing therefore on ethno-finance will strengthen the wider aspects of understanding and accepting that knowledge is more than just the facts taught and learnt in school and university.

It is imperative that researchers and other participants in indigenous knowledge systems change their operational terms, and break down and remove barriers that have been created between knowledge-holders and researchers (Morris and Pitt 1995). A framework that may be used for incorporating ethno-finance into mainstream financial research may include the following features:

- Identifying the need for incorporating ethno-finance as an important interdisciplinary research focus

- Building upon local people's knowledge that is acquired through various processes such as in loco experience and participant observations, thereby increasing the quantitative and qualitative output of research in this field

- Working with existing organizations, such as non-government organizations and management of research in these

- Bridging the research gap between local communities and the attitude of external researchers by establishing indigenous knowledge resource and research centres as well as developing research agendas.

This framework will help in developing the following priorities:

- Documentation (with a special emphasis on ethno-finance and related databases). The indigenous knowledge systems policy of the Department of Science and Technology of South Africa provides for the creation of indigenous knowledge databases which should be harmonized with other international systems so that cross-referencing is possible (Mosimege 2004). However, as ethno-finance could be seen as a recent development within indigenous knowledge systems, much work still needs to be done in this area.

- Ethno-finance and the curriculum. Efforts by the Department of Education of South Africa to integrate indigenous knowledge systems into the curriculum will have to be strengthened in order to reach more learners within the national education system. Both educators and learners need to be exposed to ethno-finance as a spin-off of indigenous knowledge systems.

- Benefit-sharing mechanisms and models for South Africa. Legislation needs to be drafted to regulate access and benefit-sharing agreements in relation to ethno-finance and its use.

- Coordination of ethno-finance efforts and activities. Higher education institutions' efforts and activities in relation to indigenous knowledge systems activities have increased as a result of researchers accessing funding from the National Research Foundation for indigenous knowledge systems. However, supplementary trusts need to be established to protect other knowledge-holders and ensure that their interests are not excluded from the mainstream of events in ethno-finance. 
According to Howes and Chambers (1980), an important difference between scientific and indigenous knowledge lies in the ways in which phenomena are observed and ordered. While the former is characterized by a greater ability to break down data presented to the senses and reassembling them in different ways, the latter relies almost exclusively on intuition and evidence directly available to the senses. Consequently, care must be taken in designing methods of acquiring information on indigenous knowledge.

\section{Conclusion}

Knowledge systems may appear simple to outsiders but they represent mechanisms to ensure the minimal livelihoods for local people. Within the fields of agriculture and health, a large amount of progress has been achieved in an attempt to merge Western philosophies with indigenous knowledge through various paradigms and research projects in southern Africa.

Indigenous knowledge holds transformative possibilities because it provides a comprehensive understanding of cultural processes by which information is legitimate and limitless. As a sub-system, ethno-finance attracts a wide range of endless possibilities due to its lack of available research and perpetual evolution.

At present, no in-depth research is available on financial knowledge passed down through indigenous knowledge systems (ethno-finance). However, it has been proven that a large demand for a greater understanding of ethno-finance does exist. It must be emphasized that ethno-finance in South Africa includes all financial practices from all cultural groups represented by one or more of the eleven official languages.

The knowledge derived from ethno-finance will enable indigenous people to become part of a new knowledge economy that will serve as a vital driving force in the future.

\section{Acknowledgement}

Sincere gratitude is expressed to Henco van Schalkwyk, Michael Coombes and Adelè de Wet for their valuable input and comments in writing this article.

\section{References}

Ajibade, L.T. 2003. In search for methodology for the collection and evaluation of farmers' indigenous environmental knowledge. Indilinga - African Journal of Indigenous Knowledge Systems 2(1): 99-105.

Dei, G. 1999. Rethinking the role of indigenous knowledge in the academy. International Journal of Inclusive Education 4(2):111-113.

Ellen, R. and Harris, H. 1996. Concepts of indigenous environmental knowledge in scientific and development studies literature - a critical assessment. Draft Paper East-West Environmental Linkages Network Workshop 3, Canterbury.

Els, G. and Van Schalkwyk, C.H. 2006. The evolution of indigenous knowledge iIndigenous financial knowledge? Working Paper, Department of Finance and Investment 
Management, University of Johannesburg.

Flavier, J.M. 1995. The regional program for the promotion of indigenous knowledge in Asia. In: Warren, D.M., Slikkerveer, L.J. and Brokensha, D. (eds). The cultural dimension of development: indigenous knowledge systems. London: Intermediate Technology

Publications: 479-487.

Gardner, H. 1987. Frames of mind. New York: Basic Books.

Howes, M. and Chambers, R. 1980. Indigenous technical knowledge: analysis, implications and issues. In: Brokensha, D.W., Warren, D.M. and Wener, O. Indigenous knowledge system and development. USA: University Press of America.

Irving, M. 2005. Informal savings groups in South Africa: investing in social capital. Centre for Social Science Research, Working Paper No. 112.

Kok, J.A. 2005. Can models for knowledge management be successfully implemented to manage the diversity of indigenous knowledge? South African Journal of Information Management 7(4). [Online]. Available WWW: http://www.sajim.co.za. (Accessed 6 March 2006).

Loubser, J.A. 2004. Unpacking the expression 'indigenous knowledge systems'. First South African Colloquium on Indigenous Knowledge Systems, University of the Free State, Bloemfontein, 29 February - 2 March 2004.

Merriam-Webster Online. 2006. [Online]. Available WWW: http://www.webster.com. (Accessed 16 August 2006).

Morris, M.H. and Pitt, L.F. 1995. Informal sector activity as entrepreneurship: insights from a South African township. Journal of Small Business Management, 33(1):78-86.

Mosimege, M. 2004. Indigenous knowledge systems in South Africa: perspectives from the Department of Science and Technology. Indilinga - African Journal of Indigenous Knowledge Systems 3(1):78-84.

Norman, H., Snyman, I. and Cohen, M. (eds). 1996. Indigenous knowledge and its uses in Southern Africa. Pretoria: Human Sciences Research Council.

Rajasekaran, B. 1993. A framework for incorporating indigenous knowledge systems into agricultural research, extension and NGOs for sustainable agricultural development. Studies in Technology and Social Change No. 21. Ames, IA: Technology and Social Change Program, Iowa State University. [Online]. Available WWW: http://www.ciesin.org/docs/004-201/004-201.html. (Accessed 6 March 2006).

Wane, N.N. 2005. African indigenous knowledge: claiming, writing, storing, and sharing the discourse. Journal of Thought 40(2):27-46.

Warren, D.M. 1991. Using indigenous knowledge in agricultural development. World Bank Discussion Paper No. 127. Washington, D.C.: The World Bank.

Wikipedia. 2006. [Online]. Available WWW: http://www.wikipedia.com. (Accessed 16 August 2006).

World Bank. 1998. Ingenious knowledge for development: a framework for action. 
Knowledge and Learning Centre, African Region, World Bank. Washington, D.C.: The World Bank.

\section{Disclaimer}

Articles published in SAJIM are the opinions of the authors and do not necessarily reflect the opinion of the Editor, Board, Publisher, Webmaster or the Rand Afrikaans University. The user hereby waives any claim he/she/they may have or acquire against the publisher, its suppliers, licensees and sub licensees and indemnifies all said persons from any claims, lawsuits, proceedings, costs, special, incidental, consequential or indirect damages, including damages for loss of profits, loss of business or downtime arising out of or relating to the user's use of the Website.

Published by InterWord Communications for Department of Information and Knowledge Management, University of Johannesburg 